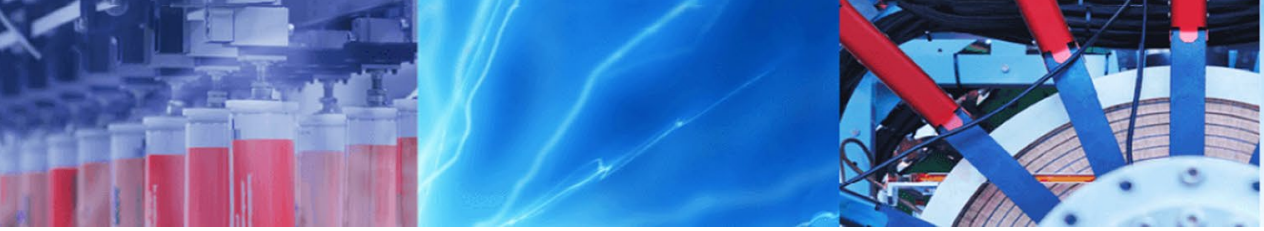

Research Article

\title{
Effects of nanomaterials on the mechanical properties of epoxy hybrid composites
}

\author{
Ömer Faruk Erkendirci ${ }^{1}$ Ahmet Avci ${ }^{2}$
}

Received: 29 January 2020 / Accepted: 31 March 2020 / Published online: 6 April 2020

(c) Springer Nature Switzerland AG 2020

\begin{abstract}
In this study, the effects of nanoparticles added to a newly developed hybrid composite material are examined. We investigated enhancing mechanical properties of plain weave (PW) carbon and glass fiber fabric/epoxy resin hybrid composite material we had developed by adding nanomaterials into the composition. For this purpose, we selected silica $\left(\mathrm{SiO}_{2}\right)$ nanoparticles and carbon nanotubes (CNT). The two different nanomaterials are added into epoxy resin (L160) in four different combinations, which are $\mathrm{SiO}_{2}, \mathrm{CNT}+\mathrm{SiO}_{2}$ and $\mathrm{CNT}$ together and none, and in five different thickness, which are laminations of three, five, seven, eleven and fifteen layers. We then tested these four mixtures in five thickness making up twenty combinations in the area of mechanical properties using tension test methods. Results of the tests in stressstrain graphs are shared in detail by displaying the mechanical properties of epoxy hybrid composite materials in tables and load-extension figures. The results and their causes are discussed giving a general conclusion of the nanomaterial enhancement properties of the new hybrid composite.
\end{abstract}

Keywords Hybrid composites · Nano materials · Epoxy · Mechanical properties · Tension tests

\section{Introduction}

For decades, polymer matrix based nanocomposites have been used, studied and investigated intensely in all engineering disciplines and some industrial areas i.e. defense, automotive, space, etc. In particularly, epoxy polymer composites reinforced with nanomaterials have continually attracted growing interest due to their specialty and ravishing properties as well as their exclusive applications in various industrial areas. The nanomaterials used in epoxy polymer composites notably improve their mechanical properties and performance. The properties of epoxy polymer nanocomposites depend upon the chemistry of matrices, nature, and uniformity of nanomaterials in matrices and the method in which they are set up for attaining desired mechanical properties and physical characteristics.
In this sense, glass and carbon weave fibers and nanomaterials reinforced polymer epoxy composites products using vacuum-assisted resin transfer molding (VARTM) method improving properties such as strength, conductivity, gas permeability, transparency, and non-flammability compared to unmodified polymers as well as polymerbased composite materials used in various fields. Especially in automotive, aerospace and packaging industries as well as the polymer hybrid nanocomposites are widely used for several areas, but technical orders in terms of production processes, mechanical properties, impact resistance, and the damage mechanisms are scant.

Additionally, in the literature, there are numerous articles related to this subject and especially some researchers have investigated and studied mechanical and other properties of nanocomposites intensively. Tjong

$\triangle$ Ömer Faruk Erkendirci, omererkendirci@aydin.edu.tr; oferkendirci@gmail.com | ${ }^{1}$ Mechanical Engineering Department, Faculty of Engineering, Istanbul Aydin University, 34000 Istanbul, Turkey. ${ }^{2}$ Biomedical Engineering Department, Faculty of Engineering, Necmettin Erbakan University, 42000 Konya, Turkey. 
[1] reported current developments on the processing, structure and mechanical properties of polymer nanocomposites reinforced with respective layered silicates, ceramic nanoparticles and carbon nanotubes (CNT) which will later be addressed. Agag et al. [2] studied the thermal expansion coefficient of the BPDA/PDA polyimide film decreased of the inclusion of clay. Crosby and Lee [3] investigated the nano effect on the mechanical properties and discussed three components of important properties the general polymer nanocomposite: polymer matrix, nanoscale filler, and interfacial region. Alexandre et al. [4] studied polyethylene layered silicate nanocomposites prepared by the polymerization filling technique: synthesis and mechanical properties. Chen et al. [5] reported scientific information that may be useful for other researchers about the interlayer expansion mechanism and thermal-mechanical properties of surface-initiated epoxy resin nanocomposites. Moreover, Paula and Robeson [6] addressed crystallization and glass transition behavior for the nano effect of the nanoparticle or fiber inclusion relative to their larger-scale counterparts. Hasegawa et al. [7] investigated the preparation and mechanical properties of surface-initiated epoxy resin nanocomposites. Haraguchi et al. [8] studied mechanical properties and structure of the nanocomposite gels (NC gels), consisting of poly and inorganic clay prepared using a wide range of clay concentration ( $25 \mathrm{~mol} \%$ against water). Modesti et al. [9] focused on the influence of processing conditions on nanocomposite structures, i.e., intercalated or exfoliated and on the enhancement of mechanical properties of polypropylene nanocomposites. Sadeghi et al. [10] work related to the effects of specimen diameter to punch diameter (span ratio) and loading velocity are experimentally studied on quasi-static punch shear (QS-PS) properties of laminate nanocomposites. Kumar et al. [11] studied the various combinations of nanomaterials and matrix materials that were used to fabricate the nanocomposite laminates with and without. Again, Jabbar et al. [12] reported indicating that the introduction of silica nanofillers on Kevlar fabrics is a promising method for enhancing mechanical properties of hybrid composite laminates. Moreover, Erkendirci and Avcl [13] studied of QS penetration resistance behavior of the single-walled carbon nanotubes (CNT) that are added into epoxy resin L160 reinforced with plain weave PW Carbon/Glass hybrid nanocomposite materials with varying thicknesses and layers. Bello et al. [14] investigated about effects of aluminium particles on mechanical and morphological properties of epoxy nanocomposites. They are reported poor tensile performance of the aluminum micro particle reinforced composites has been linked to weak interface between the matrix and the reinforcing particles which in turns depends on particle sizes.

In this study, it is important to show two different nanomaterials in one article in four types of hybrid composites in different layers, and the number of publications in this form is low. The results will help those who will work in this field. Besides, reinforcement materials such as glass and carbon weave fibers by the addition of carbon nanotubes (CNT) and silicon dioxide particles (silica, $\mathrm{SiO}_{2}$ ), reinforced polymer nanocomposites of various layer counts $(3,5,7$, 11 and 15 layers) will be produced. The production stages, the criteria and afterward mechanical properties of these materials will be determined and compared with polymer composites that have been produced in this research and thereby a clear indication of the effect of nanomaterials will be targeted.

Scope of this research is to study materials processing and mechanical properties of glass and carbon weave fibers, CNT and silica $\left(\mathrm{SiO}_{2}\right)$ reinforced polymer hybrid nanocomposites (stacking sequence: carbon weave-glass weave-carbon weave and so on others) produced using VARTM methods with various layer counts $(3,5,7,11$ and 15 layers). Additionally, effects of weight and volume fiber fractions on mechanical properties and the effect of the nanomaterials added into matrices on the polymer properties will be investigated.

\section{Experimental}

\subsection{Materials and materials processing}

Hybrid composites are fabricated using the carbon and glass plain weave (PW) fabric of various layers (three layer (3L), 5L, 7L, 11L, and 15L) by VARTM method that used in four different type epoxy hybrid composites, to see mechanical properties of CNT and $\mathrm{SiO}_{2}$ nanomaterials' effect on hybrid nanocomposite materials. Carbon-Glass layers following the stacking sequence shown in Table 1.

If we explain, four different hybrid composite materials are produced, three of them being hybrid nanocomposites

Table 1 Stacking sequence of pw carbon (C)-glass (G)/epoxy resin composite laminates

\begin{tabular}{ll}
\hline $\begin{array}{l}\text { Material } \\
\text { Number of layer }\end{array}$ & $\begin{array}{l}\text { Carbon-glass } \\
\text { Stacking sequence }\end{array}$ \\
\hline 3 & {$[\mathrm{C} / \mathrm{G} / \mathrm{C}]$} \\
5 & {$[\mathrm{C} / \mathrm{G} / \mathrm{C} / \mathrm{G} / \mathrm{C}]$} \\
7 & {$[\mathrm{C} / \mathrm{G} / \mathrm{C} / \mathrm{G} / \mathrm{C} / \mathrm{G} / \mathrm{C}]$} \\
11 & {$[\mathrm{C} / \mathrm{G} / \mathrm{C} / \mathrm{G} / \mathrm{C} / \mathrm{G} / \mathrm{C} / \mathrm{G} / \mathrm{C} / \mathrm{G} / \mathrm{C}]$} \\
15 & {$[\mathrm{C} / \mathrm{G} / \mathrm{C} / \mathrm{G} / \mathrm{C} / \mathrm{G} / \mathrm{C} / \mathrm{G} / \mathrm{C} / \mathrm{G} / \mathrm{C} / \mathrm{G} / \mathrm{C} / \mathrm{G} / \mathrm{C}]$} \\
\hline
\end{tabular}


(CNT hybrid nanocomposite, $\mathrm{SiO}_{2}$ hybrid nanocomposite, and CNT-SiO ${ }_{2}$ hybrid nanocomposite) and one of them is hybrid composite (no nanomaterials).

In this sense, the homogeneity, amount and distribution of nanofillers can greatly affect the mechanical properties of nanocomposites because these two parameters affect the mechanical properties of the nanocomposite materials. Therefore, in this paper, the homogenous distribution of CNT and silica nanoparticles $\left(\mathrm{SiO}_{2}\right)$ into polymers are considered as important. First, nanotubes transferred into polymers will be mixed by using ultrasonic stirrer and will be obtaining a homogenized solution by using a mechanical mixer. De-gasing operation will be done in a vacuum oven after production to get rid of the air, which would possibly be solved while stirring. After that, composite nanomaterials will be produced using this mixture by the VARTM method (Fig. 1.).

Carbon-Glass/epoxy L160 hybrid composites (Type 1) are made using PW carbon and glass fabric $\left(200 \mathrm{~g} / \mathrm{m}^{2}\right.$ and $\left.300 \mathrm{~g} / \mathrm{m}^{2}\right)$ cut into $(300 \times 300 \mathrm{~mm})$ sheets. The panels of various layers are infused with MGS L160 (80\% mixing rate) epoxy resin and MGS LH160 (4\% mixing rate), MGS LH260S (16\% mixing rate) hardeners using vacuum-assisted transfer mol (VARTM) process. The composite panels are cured at room temperature $\left(\mathrm{RT}, 23^{\circ} \mathrm{C}\right)$ for $12 \mathrm{~h}$ under vacuum.

Carbon-Glass/epoxy L160 + CNT (Type 2), CarbonGlass/epoxy $\mathrm{L} 160+\mathrm{SiO}_{2}$ (Type 3) and Carbon-Glass/ epoxy $\mathrm{L} 160+\mathrm{CNT}^{-\mathrm{SiO}_{2}}$ (Type 4) hybrid nanocomposites are produced using the same fabric of various layers by the VARTM method. During processing, nanomaterials added in epoxy resin L160 before vacuum. CNT (single-walled, OD $=1-2 \mathrm{~nm}-0.3 \%$ weight ratio of epoxy resin L160) is added to epoxy resin L160 and then mixed by mechanical and ultrasonic mixers sequentially, and then this mixture is used for the production of Type 2 nanocomposite material by VARTM method. Similarly, $\mathrm{SiO}_{2}(15-50 \mathrm{~nm}-4 \%$ weight ratio of epoxy resin L160) are added for production of Type 3 nanocomposite material and finally, CNT(single-walled, $\mathrm{OD}=1-2 \mathrm{~nm}-0.3 \%$ weight ratio of epoxy resin $\mathrm{L} 160$ )

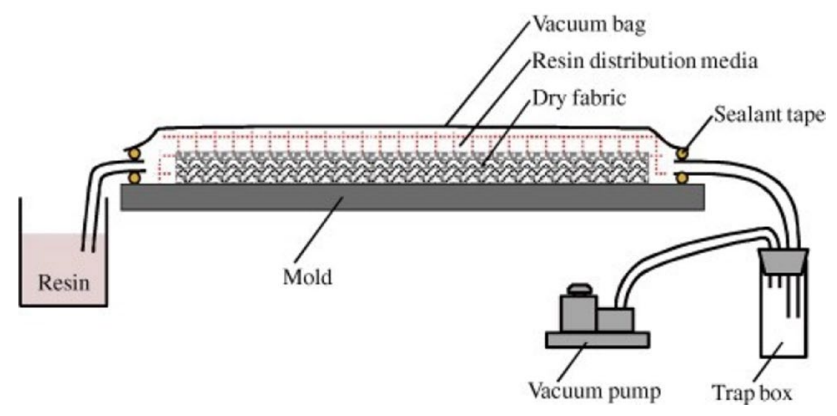

Fig. 1 Schematic view of VARTM method and $\mathrm{SiO}_{2}(15-50 \mathrm{~nm}-4 \%$ weight ratio of epoxy resin L160) are added for production of Type 4 hybrid nanocomposites (Table 2 ).

\subsection{Tension tests}

The static tension tests are carried on four different types of hybrid composite materials (six layers each of them, as $3 \mathrm{~L}, 5 \mathrm{~L}, 7 \mathrm{~L}, 11 \mathrm{~L}$, and $15 \mathrm{~L}$ ) and various thickness concerning the ASTM D 3039 standard. Test specimens $(250 \times 25$ $\mathrm{mm}$ ) are prepared as shown in Fig. 2a, the experiments are carried out by the use of Universal Instron Tensile Testing Machine of $50 \mathrm{KN}$ capacity (Fig. 2b). The tension load velocity is $0.5 \mathrm{~mm} / \mathrm{min}$ at room temperature (RT). The static tension tests are recorded and captured with a digital video camera. During the video recording, the load and displacement or extension values are stored in the Universal Instron Tensile Testing Machine's data acquisition computer. Figure 3 shows Tension Load - Extension graphs of all types and layers of hybrid or hybrid nanocomposite materials. Graphs are plotted to compare layers and materials ( $3 \mathrm{~L}, 5 \mathrm{~L}, 7 \mathrm{~L}, 11 \mathrm{~L}$, and $15 \mathrm{~L}$ ).

The thickness, dimensions, and mass are measured to calculate the density and areal density $(A D)$ of the hybrid

Table 2 Material types and contents of hybrid composite material

\begin{tabular}{ll}
\hline & Fibers/matrice + nanomaterials \\
\hline Type 1 & Carbon-glass/epoxy L160+ no nanomaterial \\
Type 2 & Carbon-glass/epoxy L160+CNT \\
Type 3 & Carbon-glass/epoxy L160+SiO \\
Type4 & Carbon-glass/epoxy L160+CNT-SiO 2 \\
\hline
\end{tabular}

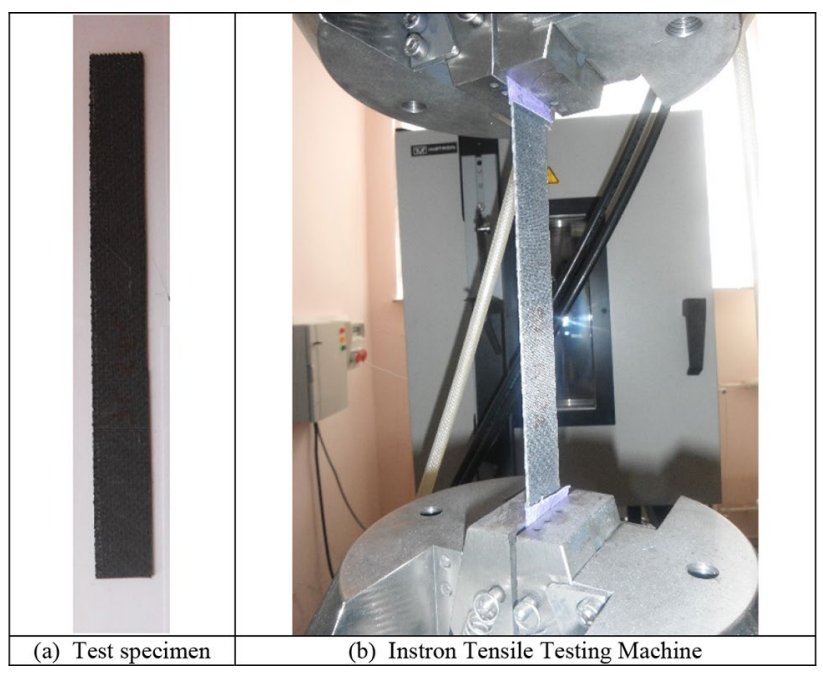

Fig. 2 Photografs of test specimen and universal Instron tensile test machine 

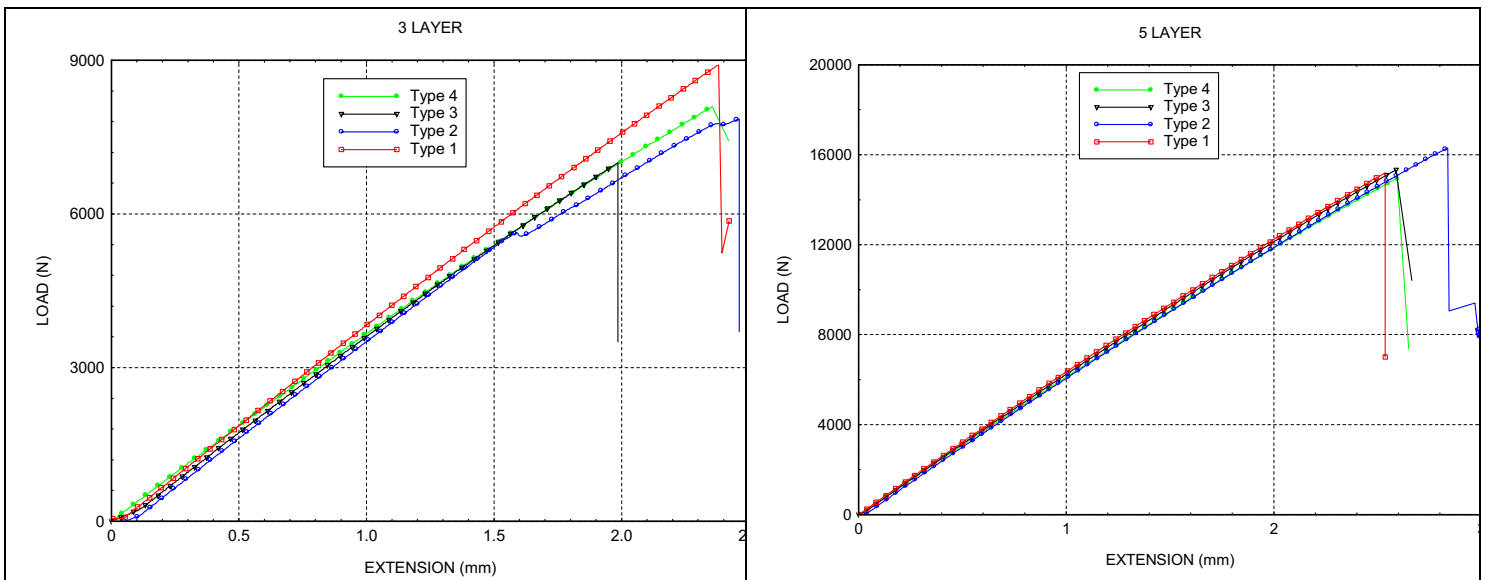

(a) $3 \mathrm{~L}$

(b) $5 \mathrm{~L}$

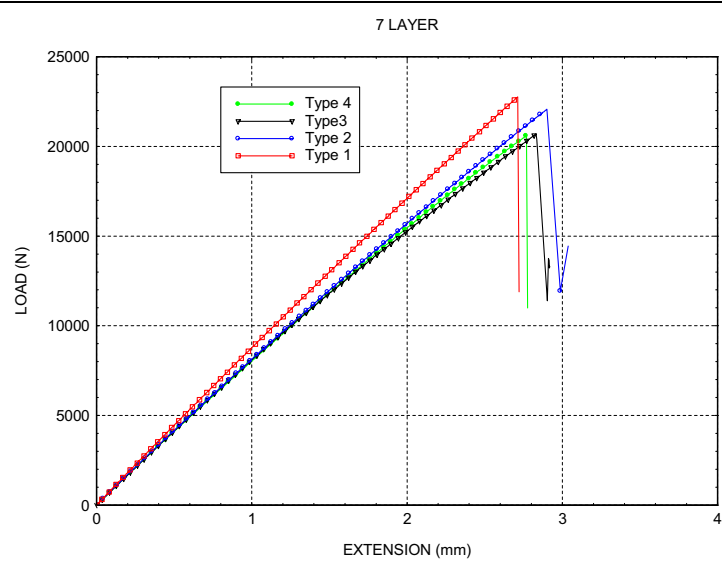

(c) $7 \mathrm{~L}$

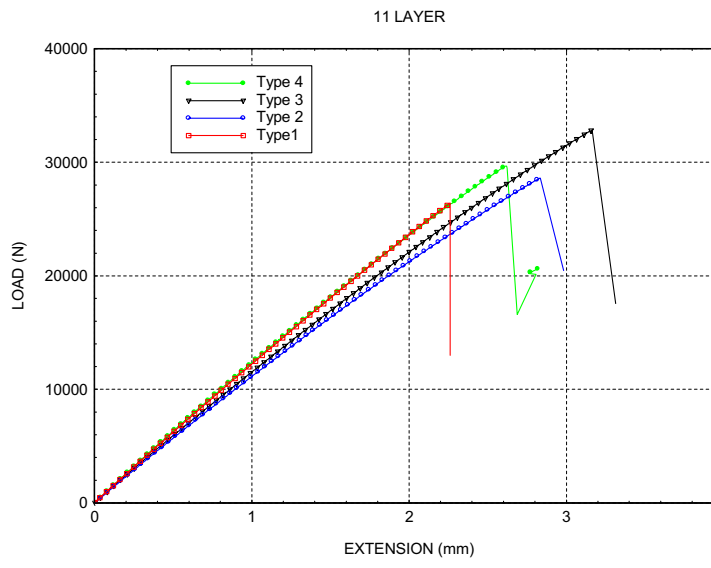

(d) $11 \mathrm{~L}$

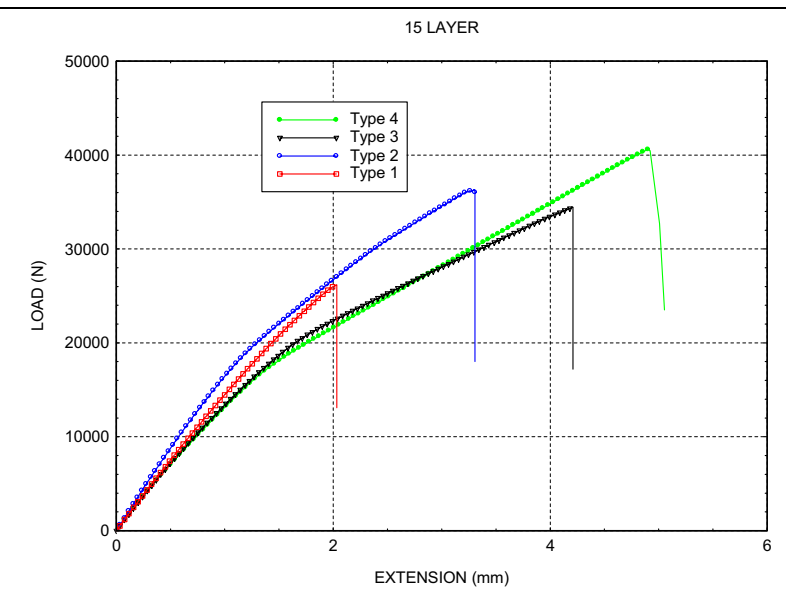

(e) $15 \mathrm{~L}$

Fig. 3 Tension load-extension plots for all types and layers 
Table 3 Mechanical, mass and geometric properties of all types $3 \mathrm{~L}$ hybrid composite materials

Table 4 Mechanical, mass and geometric properties of all types $5 \mathrm{~L}$ hybrid composite materials

Table 5 Mechanical, mass and geometric properties of all types 7L hybrid composite materials

Table 6 Mechanical, mass and geometric properties of all types $11 \mathrm{~L}$ hybrid composite materials

Table 7 Mechanical, mass and geometric properties of all types $15 \mathrm{~L}$ hybrid composite materials

\begin{tabular}{lcllllll}
\hline \multicolumn{2}{l}{ 3L hybrid composite materials } \\
\hline & $\sigma_{\max }(\mathrm{MPa})$ & $\varepsilon \%$ & $\begin{array}{l}\mathrm{E} \\
(\mathrm{GPa})\end{array}$ & $\rho_{\mathrm{c}}\left(\mathrm{g} / \mathrm{cm}^{3}\right)$ & $\mathrm{AD}\left(\mathrm{g} / \mathrm{cm}^{2}\right)$ & $\begin{array}{l}v_{f} \\
\%\end{array}$ & $H_{\mathrm{c}}(\mathrm{mm})$ \\
\hline Type1 & 332 & 1.39 & 23.9 & 1.79 & 1.9153 & 36.85 & 1.07 \\
Type2 & 393 & 1.46 & 26.920 & 1.78 & 2.1004 & 39.651 & 1.18 \\
Type3 & 496 & 2.41 & 20.6 & 1.84 & 1.748 & 27 & 0.95 \\
Type4 & 433 & 1.38 & 31.4 & 2.06 & 1.7304 & 55.079 & 0.84 \\
\hline
\end{tabular}

\begin{tabular}{llllllll}
\hline \multicolumn{2}{l}{ 5L hybrid composite materials } \\
\hline & $\sigma_{\max }(\mathrm{MPa})$ & $\varepsilon \%$ & $\begin{array}{l}\mathrm{E} \\
(\mathrm{GPa})\end{array}$ & $\rho_{C}\left(\mathrm{~g} / \mathrm{cm}^{3}\right)$ & $\mathrm{AD}\left(\mathrm{g} / \mathrm{cm}^{2}\right)$ & $v_{f} \%$ & $H_{C}(\mathrm{~mm})$ \\
\hline Type1 & 390 & 1.48 & 26.368 & 1.98 & 2.6532 & 37.7 & 1.34 \\
Type2 & 401 & 1.66 & 24.148 & 1.94 & 2.716 & 41.566 & 1.4 \\
Type3 & 474 & 1.51 & 31.428 & 2.01 & 3.2361 & 40.437 & 1.61 \\
Type4 & 460 & 1.52 & 30.261 & 2.02 & 2.525 & 61.225 & 1.25 \\
\hline
\end{tabular}

\begin{tabular}{llllllll}
\hline \multicolumn{7}{l}{ 7L hybrid composite materials } \\
\hline & $\sigma_{\max }(\mathrm{MPa})$ & $\varepsilon \%$ & $\begin{array}{l}\mathrm{E} \\
(\mathrm{GPa})\end{array}$ & $\rho_{C}\left(\mathrm{~g} / \mathrm{cm}^{3}\right)$ & $\mathrm{AD}\left(\mathrm{g} / \mathrm{cm}^{2}\right)$ & $\begin{array}{l}v_{f} \\
\%\end{array}$ & $H_{C}(\mathrm{~mm})$ \\
\hline Type1 & 412 & 1.59 & 25.920 & 2.09 & 4.9324 & 35.31 & 2.36 \\
Type2 & 426 & 1.7 & 25.075 & 2.03 & 3.674 & 35.96 & 1.81 \\
Type3 & 384 & 1.66 & 24.000 & 2.05 & 3.7925 & 46.381 & 1.85 \\
Type4 & 406 & 1.72 & 25.102 & 2.1 & 3.591 & 48.989 & 1.71 \\
\hline
\end{tabular}

\begin{tabular}{llllllll}
\hline \multicolumn{1}{l}{ 11L hybrid composite materials } & & & & \\
\hline & $\sigma_{\max }(\mathrm{MPa})$ & $\varepsilon \%$ & $\begin{array}{l}\mathrm{E} \\
(\mathrm{GPa})\end{array}$ & $\rho_{C}\left(\mathrm{~g} / \mathrm{cm}^{3}\right)$ & $\mathrm{AD}\left(\mathrm{g} / \mathrm{cm}^{2}\right)$ & $\begin{array}{l}\mathrm{v}_{f} \\
\%\end{array}$ & $H_{C}(\mathrm{~mm})$ \\
\hline Type1 & 371 & 1.46 & 25.400 & 2.13 & 5.7084 & 38.44 & 2.68 \\
Type2 & 401 & 1.51 & 26.538 & 2.14 & 5.735 & 40.533 & 2.68 \\
Type3 & 480 & 1.98 & 24.250 & 2.16 & 5.8536 & 44.997 & 2.71 \\
Type4 & 437 & 1.53 & 28.600 & 2.12 & 5.7876 & 48.457 & 2.73 \\
\hline
\end{tabular}

\begin{tabular}{llllllll}
\hline 15L hybrid composite materials & & & & \\
\hline & $\sigma_{\max }(\mathrm{MPa})$ & $\varepsilon \%$ & $\begin{array}{l}\mathrm{E} \\
(\mathrm{GPa})\end{array}$ & $\rho_{C}\left(\mathrm{~g} / \mathrm{cm}^{3}\right)$ & $\mathrm{AD}\left(\mathrm{g} / \mathrm{cm}^{2}\right)$ & $\begin{array}{l}\mathrm{v}_{f} \\
\%\end{array}$ & $H_{C}(\mathrm{~mm})$ \\
\hline Type1 & 373 & 1.48 & 25.015 & 2.16 & 7.452 & 46.07 & 3.45 \\
Type2 & 471 & 1.94 & 24.326 & 2.15 & 7.31 & 45.431 & 3.4 \\
Type3 & 476 & 1.89 & 25.195 & 2.19 & 8.1468 & 56.116 & 3.72 \\
Type4 & 499 & 1.92 & 26.000 & 2.13 & 7.7745 & 49.593 & 3.65 \\
\hline
\end{tabular}




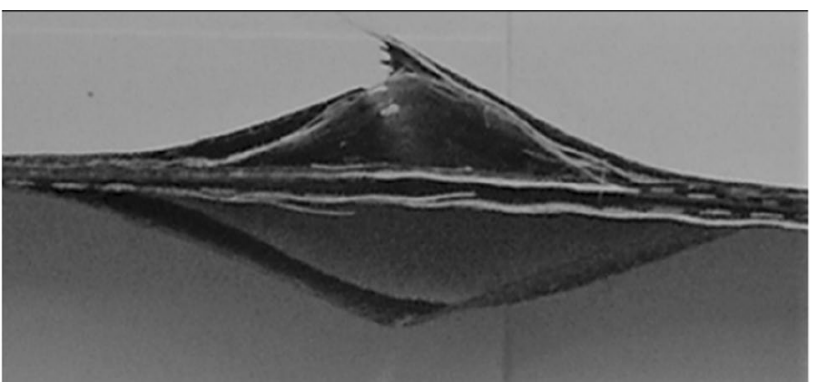

Fig. 4 The optical damage stereo sample photograph after the tensile test

composite and nanocomposite materials. Density $(\rho)$ and fiber volume fraction $\left(V_{f}\right)$ of the hybrid composite laminates are measured following ASTM D2584 standard. The areal densities of hybrid composite panels are calculated from the measured density and thickness of the hybrid composite laminates,

$A D=\rho_{c} H_{c}$

where $\rho_{c}$ is the average density and $H_{c}$ is the average thickness of composite panels. Mass end geometric properties of Type 1, Type 2, Type 3 and Type 4 hybrid composite materials for all layers $(3 \mathrm{~L}, 5 \mathrm{~L}, 7 \mathrm{~L}, 11 \mathrm{~L}$, and $15 \mathrm{~L}$ ) sequentially are presented in Tables 3, 4, 5, 6 and 7.

\section{Damage mechanisms}

After the tensile tests, fractured or damaged specimens are investigated. As a result, brittle fiber fracture and matrix cracks have been observed in all types of PW Carbon-PW Glass/Epoxy Resin L160) composite material systems as expected. During the tensile tests, 96 test specimens are tested. Since there are many specimens, only one of them is shown in this article as a sample. Brittle fiber fracture and matrix cracks, fiber pull out have been observed in all types of laminates. The optical damage stereo sample photograph after the tensile test is presented in Fig. 4. Besides, scanning electron microscope (SEM) images of fiber fracture and matrix cracks of the hybrid composite and hybrid nanocomposites material systems for all types are shown in Fig. 5.

\section{Discussion and conclusion}

In this study, four different types of nanocomposite materials [Carbon-Glass/epoxy (Type 1), Carbon-Glass/ epoxy + CNT (Type 2), Carbon-Glass/epoxy $+\mathrm{SiO}_{2}$ (Type 3) and Carbon-Glass/epoxy + CNT-SiO ${ }_{2}$ (Type 4)] were studied to see the effect of the nanomaterials on the mechanical properties of hybrid nanocomposites with different thickness, i.e., $H_{C}=1.07-3.75-\mathrm{mm}$. Carbon-glass/epoxy hybrid composites (Type 1) laminates were used as the basic material and the other three types were compared with that one. Mass and geometric properties of hybrid composites were shown on the tables to compare them. Tests were performed to measure stress, strain and elastic modulus of different composite material laminates. It was detected that the force-displacement behavior of hybrid composite and nanocomposites are different from basic hybrid composites and were shown on the load-displacement graphs and tables in a detailed form.

The conclusions obtained from this study are as follows,

1. The maximum load of the hybrid composite and nanocomposite materials occurred sequentially in order of; Type 3, Type 4, Type 2 and Type 1. So nanomaterials affected and increased the extension load capacity of the composite laminates for all types as shown in Tables 3, 4, 5, 6 and 7 and Fig. 1.

2. Modulus of elasticity was found to be considered very close to each other for all types of composite laminates. This shows that the results are stable and the production quality of composite materials is good.

3. Densities were very close values to each other concerning all types.

4. The increasing ratio of extension load capacity for all types of composite materials was linear concerning laminate thickness.

5. Nanomaterials affected mechanical properties of composite materials, therefore most efficient nanomaterials on mechanical properties in sequential order were $\mathrm{SiO}_{2}, \mathrm{CNT}-\mathrm{SiO}_{2}$ and CNT.

6. Brittle fiber fracture and matrix cracks have been observed in all types PW Carbon-PW Glass/Epoxy Resin L160) composite material system as expected 


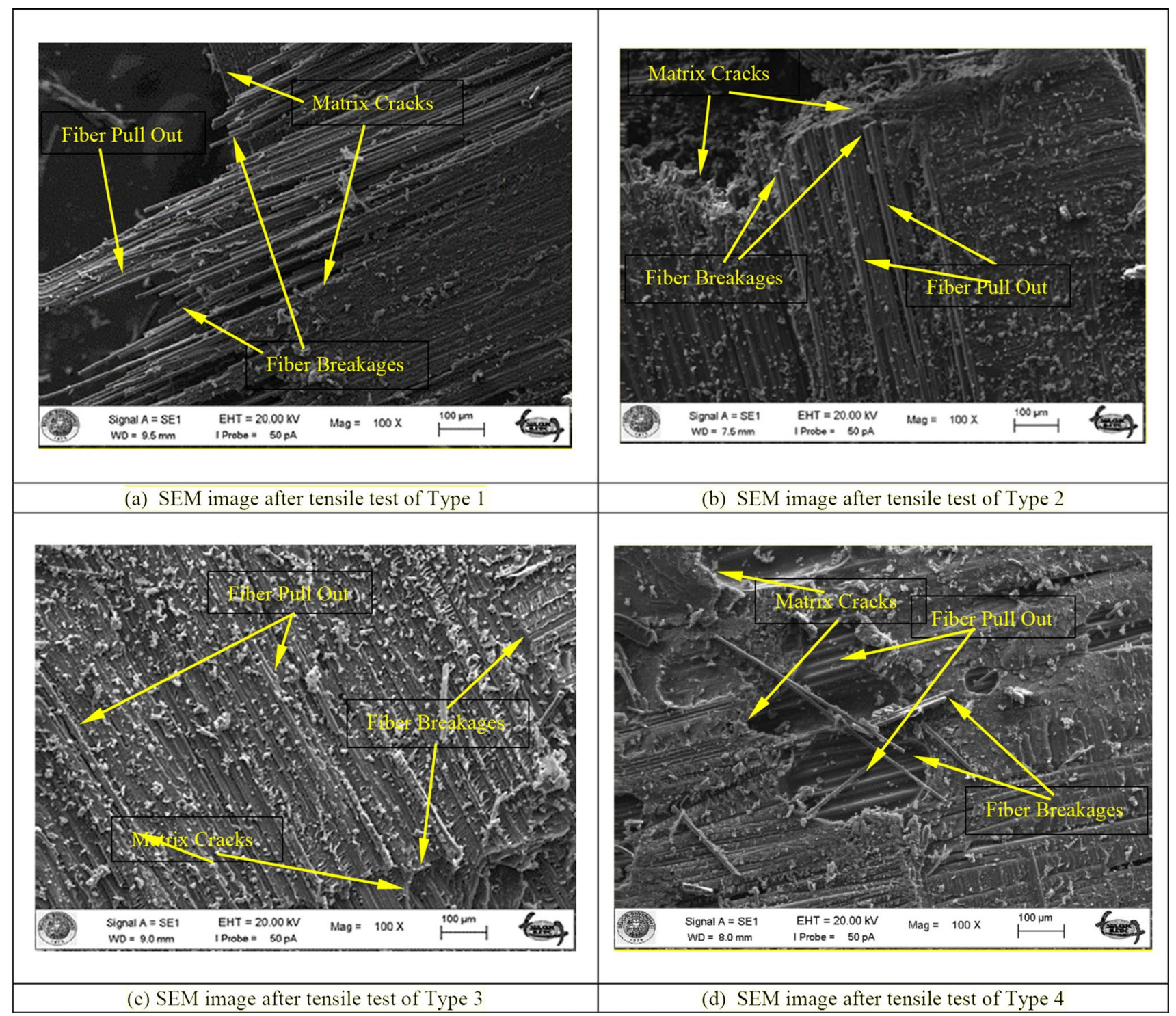

Fig. 5 Scanning electron microscope (SEM) images of fiber breakages, fiber pull out, and matrix cracks of PW carbon-PW glass/epoxy resin L160 for all types

Acknowledgements This research was supported by the Scientific and Technological Research Council of Turkey (TUBITAK) Project Number: 213M631.

\section{References}

1. Tjong SC (2006) Structural and mechanical properties of polymer nanocomposites. Mater Sci Eng R 53(3-4):73-197

2. Agag $T$, Koga $T$, Takeichi $T$ (2001) Studies on thermal and mechanical properties of polyimide-clay nanocomposites. Polymer 42(8):3399-3408

3. Crosby AJ, Lee J-Y (2007) Polymer nanocomposites: the "nano" effect on mechanical properties. J Polym Rev 47(2):217-229
4. Alexandre M, Dubois P, Sun T, Garces JM, Jérôme R (2002) Polyethylene-layered silicate nanocomposites prepared by the polymerization-filling technique: synthesis and mechanical properties. Polymer 43(8):2123-2132

5. Chen J-H, Dpoliks M, Kober C, Zhang Y, Wiesner U, Giannelis E (2002) Study of the interlayer expansion mechanism and thermal-mechanical properties of surface-initiated epoxy nanocomposites. Polymer 43(18):4895-4904

6. Paula DR, Robeson LM (2008) Polymer nanotechnology: nanocomposites. Polymer 49(15):3

7. Hasegawa N, Kawasumi M, Kato M, Usuki A, Okada A (1998) Preparation and mechanical properties of polypropylene-clay hybrids using a maleic anhydride-modified polypropylene oligomer. J Appl Polym Sci 67:87-92

8. Haraguchi K, Li H-J (2006) Mechanical properties and structure of polymer-clay nanocomposite gels with high clay content. Macromolecules 39(5):1898-1905 
9. Modesti M, Lorenzetti A, Bon D, Besco S (2005) Effect of processing conditions on morphology and mechanical properties of compatibilized polypropylene nanocomposites. Polymer 46(23):10237-10245

10. Sadeghi M, Pol MH (2018) Experimental studies on the punch shear characterization of glass/epoxy/CNTs laminate nanocomposites. Polym Compos 39(S4):2096-2105

11. Kumar MS, Raju NM, Sampath PS, Jayakumari LS (2014) Effects of nanomaterials on polymer composites-an expatiate view. Rev Adv Mater Sci 38(1):40-54

12. Jabbar M, Karahan M, Nawab Y, Ashraf N, Hussain T (2019) Effect of silica nanoparticles on mechanical properties of Kevlar/epoxy hybrid composites. J Text Inst 110(4):606-613
13. Erkendirci ÖF, Avcı A (2020) Quasi-static impact resistance and damage mechanisms of polymer hybrid nanocomposites. Plast Rubber Compos 49(1):25-34

14. Bello SA, Agunsoye JO, Adebisi JA, Suleiman BH (2017) Effects of aluminium particles on mechanical and morphological properties of epoxy nanocomposites. Acta Periodica Technol 48:25-38

Publisher's Note Springer Nature remains neutral with regard to jurisdictional claims in published maps and institutional affiliations. 